\title{
INTERAÇÃO ENTRE SAÚDE E AMBIENTE: OFICINAS DE RECICLAGEM NA REABILITAÇÃO DE USUÁRIOS DE SUBSTÂNCIAS PSICOATIVAS
}

\section{INTERACTION BETWEEN HEALTH AND ENVIRONMENT: RECYCLING OFFICES IN THE REHABILITATION OF USERS OF PSYCHOACTIVE SUBSTANCES}

\section{INTERACCIÓN ENTRE SALUD Y MEDIO AMBIENTE: TALLERES DE RECICLAJE EN LAS USUARIAS DE SUSTANCIAS PSICOACTIVAS REHABILITACIÓN}

\author{
Daiana Foggiato de Siqueira ${ }^{1}$, Luis Felipe Pissaia ${ }^{2}$, Claudete Moreschi ${ }^{3}$
}

\begin{abstract}
RESUMO
Objetivo: Objetivou-se conhecer o significado das oficinas de artesanatos com materiais recicláveis para usuários em tratamento de desintoxicação de substâncias psicoativas. Método: A pesquisa apresenta uma abordagem qualitativa, realizada com quinze pacientes que se encontravam internados para tratamento na unidade para usuários de substâncias psicoativas e que fizeram parte das oficinas de artesanato com materiais recicláveis. Resultados: A partir da análise dos dados, resultaram as seguintes categorias: conhecendo sentimentos do vivido; atribuindo importância às oficinas de materiais recicláveis; percebendo as oficinas como atividade educativa sustentável; influência das mídias sociais. Os usuários evidenciaram a importância das oficinas de recicláveis desenvolvidas durante o tratamento de desintoxicação, sendo considerada uma atividade educativa sustentável. Conclusão: Neste sentido torna-se fundamental que o profissional da saúde seja inovador com vistas a reduzir as manifestações diretas do uso de substâncias psicoativas e despertar uma consciência socioambiental, na busca do viver saudável dos indivíduos em sua singularidade.
\end{abstract}

Descritores: Transtornos Relacionados ao Uso de Substâncias; Serviços de Saúde Mental; Hospitalização; Educação em Saúde.

\begin{abstract}
Purpose: The aim was to understand the meaning of craft workshops using recyclable materials to users in detoxification treatment of psychoactive substances. Method: The research presents a qualitative approach, performed with fifteen patients who were admitted to treatment period in the unit for addicts and who were part of the craft workshops using recyclable materials. Results: From the analysis of the data resulted in the following categories: knowing the feelings lived; assigning importance to workshops recyclables; realizing the workshops as sustainable educational activity; influence of social media. Participants highlighted the importance of recycling workshops developed during the detox

\footnotetext{
${ }^{1}$ Enfermeira. Mestra em Enfermagem. Doutoranda em Enfermagem pelo PPGENF/UFSM.

${ }^{2}$ Enfermeiro. Mestrando em Ensino pelo Centro Universitário UNIVATES.

${ }^{3}$ Enfermeira. Doutora em Ambiente e Desenvolvimento.
} 
treatment and is considered an educational activity sustainable. Conclusion: Therefore it is essential professional nurse to adopt entrepreneurial attitudes in order to reduce the direct manifestations of drug use and arouse ecological awareness, in the order of the well being of the people in their one way.

Descriptors: Disturbances Related to Substance Use; Mental Health Services; Hospitalization; Health Education.

\section{RESUMEN}

Objetivo: El objetivo fue conocer el significado de talleres con manualidades recicladas para los usuarios en tratamiento de desintoxicación de sustancias materiales. Método: Presenta un enfoque cualitativo, realizada con quince pacientes hospitalizados que recibieron tratamiento para los adictos a las drogas en la unidad y que formaban parte de los talleres de manualidades utilizando materiales reciclables. Resultados: Los datos analizados resultaron las siguientes siguientes categorías: conocer los sentimientos vivían; asignando importancia a talleres reciclables, la realización de los talleres como actividad educativa sostenible; influencia de los medios sociales. Reveló la importancia de los talleres de reciclaje desarrollados durante el tratamiento de desintoxicación y se considera una actividad educativa sostenible. Conclusión: Por lo tanto es esencial que los profesionales de la salud adopten actitudes empresariales con el fin de reducir las manifestaciones directas del consumo de drogas y despertar la conciencia ambiental en la búsqueda de una vida saludable de las personas en su singularidad.

Descriptores: Trastornos Relacionados al Consumo de Sustancias; Servicios de Salud Mental; Hospitalización; Educación en Salud.

\section{INTRODUÇÃO}

$\mathrm{Na}$ sociedade contemporânea, são enfrentados diversos desafios relacionados com o uso e abuso de substâncias licitas e ilícitas por todas as faixas etárias da população. Em uma instituição hospitalar, destaca-se a preocupação com o aumento no número de usuários de substâncias psicoativas em tratamento para desintoxicação e a falta de ocupação necessária para estes indivíduos.

Diante das novas tendências de consumo, o âmbito hospitalar devido sua natureza assistencial, presta atendimento a diversas situações emergentes, como o problema das substâncias psicoativas. Em levantamento domiciliar sobre o uso de drogas psicotrópicas no Brasil, envolvendo as 108 maiores cidades do Brasil, constatou-se que $22,8 \%$ da população já havia feito uso de alguma droga psicotrópica na vida. ${ }^{1}$

Conforme pesquisa realizada com usuários em fase de tratamento para desintoxicação de substâncias psicoativas, é possível afirmar que os indivíduos, 
muitas vezes, apesar do caos evidenciado em suas vidas, buscam alternativas para recuperar a sua história de vida. Dentre as estratégias apontadas, destaca-se a necessidade de uma ocupação mental, acompanhada de atividades prazerosas. ${ }^{2}$

Frente a está nova realidade, os profissionais de saúde, vêm se mobilizando para a implantação de atitudes empreendedoras que possam promover estratégias de possível ocupação/renda para os usuários em seu período de reinserção social, visando a promoção da educação socioambiental com os usuários de substâncias psicoativas.

É imprescindível que as práticas educativas e de pesquisa na saúde cooperem com atividades que tenham significado e que promovam um (re)pensar e um (re)organizar das maneiras de refletir e atuar mediante o processo de viver saudável levando em conta suas repercussões e interações com as questões ambientais. ${ }^{3}$ Para tanto, faz-se necessário que cada profissional se perceba como ator social, apropriando-se da consciência ambiental para atuar de forma responsável e ambientalmente correta. Essas ações necessitam favorecer a busca de uma ética ecocêntrica, a fim de estabelecer uma relação de horizontalidade entre os seres humanos e os demais elementos do ambiente. $^{4}$

Dentre as ações contribuintes a educação socioambiental, a reciclagem merece destaque, pois contribui com intensidade para a preservação do meio ambiente. Na direção da reciclagem, por meio da construção de artesanatos com os resíduos, é possível despertar a criatividade, uma consciência socioambiental, obter atividades ocupacionais e proporcionar recursos financeiros para os envolvidos. Esse fato vem ao encontro da realidade dos usuários de substâncias psicoativas em processo de desintoxicação, com a necessidade de instigá-los ao cuidado sustentável e a manter um processo terapêutico durante o período de internação.

Frente ao exposto, questiona-se: qual o significado das oficinas de artesanatos com materiais recicláveis para usuários em tratamento de desintoxicação de substâncias psicoativas? Neste sentido, o objetivo deste estudo consistiu em conhecer o significado das oficinas de artesanatos com materiais recicláveis para usuários em tratamento de desintoxicação de substâncias psicoativas. 


\section{MÉTODO}

Trata-se de uma pesquisa qualitativa, descritiva e exploratória que buscou conhecer o significado das oficinas de artesanatos com materiais recicláveis para usuários em tratamento de desintoxicação de substâncias psicoativas. Foi desenvolvida em uma instituição hospitalar localizada na região leste do município de Santa Maria/RS.

Participaram do estudo quinze usuários que se encontravam internados em período de tratamento na unidade para usuários de substâncias psicoativas e que fizeram parte das oficinas de artesanato com materiais recicláveis. Estes foram escolhidos de forma aleatória e mediante aceite de participar da pesquisa, onde foi solicitada a assinatura do Termo de Consentimento Livre e Esclarecido (TCLE).

As oficinas de artesanato com materiais recicláveis foram realizadas na unidade de desintoxicação, dando ênfase à contribuição para a preservação ambiental e também com foco na sustentabilidade financeira para os mesmos, no pós-alta. Os artesanatos mais construídos por eles foram flores, bonecos e embalagens para presentes. Os produtos confeccionados foram construídos por meio dos seguintes materiais: garrafas de $500 \mathrm{ml}$ de água mineral, garrafas "pet", tampas das garrafas plásticas, embalagens de xampu, caixas de leite, rolo de papel higiênico, tampas de frasco de medicações, embalagens de iogurte, dentre outros.

A coleta de dados foi realizada por meio de uma entrevista semiestruturada, entre os meses de março a julho de 2011. A mesma teve seus áudios gravados e posteriormente transcritos. Foi embasada na seguinte questão norteadora: qual o significado que você atribui às oficinas de artesanatos com materiais recicláveis?

Para preservar o anonimato, as falas dos participantes da pesquisa foram identificadas pela letra "U" que é a letra inicial da palavra usuário, e numerada conforme a ordem dos discursos. A coleta de dados cessou quando, ao codificar e analisar os dados, novas propriedades não vieram a emergir.

Os dados e informações foram analisados por categorização, com base no método de Análise de Conteúdo de Bardin. ${ }^{5}$ A qual se constitui de três momentos: o primeiro consiste em uma 
frequência com identificação dos principais significados que os usuários atribuem para as oficinas realizadas com resíduos recicláveis, o segundo analisa o conteúdo que identifica as categorias que emergiram a partir dos dados coletados, e o terceiro refere-se à interpretação das categorias, conhecendo os sentimentos do vivido; atribuindo importância às oficinas de materiais recicláveis; percebendo as oficinas como atividade educativa sustentável; influência das mídias sociais.

Para atender os critérios éticos, foram seguidas as recomendações da Resolução n n 466/2012, do Conselho Nacional de Saúde, ${ }^{6}$ bem como a solicitação de autorização ao Comitê de Ética em Pesquisa do Centro Universitário Franciscano (UNIFRA). O projeto foi aprovado em 21 de setembro de 2009, pelo Comitê de Ética da UNIFRA, sob o n. 279/2009, registro na CONEP n. 1246.

\section{RESULTADOS}

A partir da análise dos dados resultaram quatro categorias, a saber: conhecendo os sentimentos do vivido; atribuindo importância às oficinas de materiais recicláveis; percebendo as oficinas como atividade educativa sustentável; influência das mídias sociais.

\section{Conhecendo os sentimentos do vivido}

Os participantes compreendem as oficinas como oportunidade, configurandose em ocasião de sentimentos para dialogar; divertir-se; sentir-se livre para criar, inventar e inovar em suas construções/artesanatos; refletir sobre a importância da escola; sentir-se importante, poder resgatar a confiança; e solidarizar-se com os colegas, conforme mostram os relatos a seguir:

Essas oficinas podem nos ajudar até mesmo para montar um projeto quem sabe, depois que sair daqui, para poder ajudar os outros que estão no mesmo mundo nosso. (U3)

Acho que é bem importante porque é legal, é divertida, a gente se diverte conversando com vocês e a gente aqui dentro não tem muita coisa para fazer, e lá, nas oficinas, tem muita coisa para fazer. (U7)

As atividades são bem importantes, lá sinto liberdade, posso inventar, desenhar e pintar, vocês nos deixam fazer a vontade, parece que confiam na gente [...] aquele dia lá, por exemplo, que pintamos as cestas de pascoa, eu adoro pintar, é uma das matérias do colégio que eu adorava, eu sempre tirava 10, parecia que eu estava na escola. (U13)

Com isso, reconhecem as oficinas como uma oportunidade, que 
posteriormente, por meio de projetos, podem ser desenvolvidas no âmbito de sua vivencia, e, assim, auxiliar os demais usuários no tratamento clínico. Essa atitude demonstra sentimentos de solidariedade por parte dos usuários, com os seus colegas, que também precisam de ajuda.

Ainda, apontam para a importância que sentem em relação ao diálogo que ocorre durante as construções das oficinas. Expressam sentimentos de descontração e convívio, evidenciando-se a importância da ferramenta do diálogo. Sentem-se importantes em conversar e serem escutados. Pode-se perceber que os usuários apresentam-se contentes em relação à confiança atribuída a eles, representando uma oportunidade para resgatar a confiança perdida em decorrência do uso de substâncias psicoativas.

Evidenciou-se, também, sentimentos de liberdade nas falas deles quando se reportam aos inventos criados durante as oficinas. Enfatizam que essas promovem atividades prazerosas, pois oferecem momentos de descontração aliados aos períodos de integração por parte dos envolvidos. Ainda, fazem uma analogia das atividades desenvolvidas nas oficinas com a escola, demonstrando sentimentos de saudades e vontade de retomar suas atividades escolares.

\section{Atribuindo importância às oficinas de materiais recicláveis}

Os usuários evidenciam a importância das oficinas de recicláveis desenvolvidas durante o tratamento de desintoxicação. Atribuem valoração a essas atividades, como oportunidade para apreender, transformar, ocupar-se e obter recursos econômicos. Como mencionam as falas, abaixo:

É uma coisa a mais pra gente fazer aqui dentro, é uma chance até pra gente aprender a fazer lá fora, se manter ocupado aqui dentro e lá fora. (U4)

Eu acho legal, as oficinas ajudam a fazer os bonequinhos, fazer as florzinhas e muitas outras coisas, achei muito legal essa oficina. (U8)

Eu acho que é bom porque é um recurso a mais pra nós, é algo a mais para fazer. (U11)

Conforme relatos acima, essas atividades significam uma oportunidade de construção e aprendizado, como também representam subsídios de ocupação e recursos financeiros, tanto, para $\mathrm{O}$ momento que se encontram internados na unidade, quanto para o período após alta hospitalar. 


\section{Percebendo as oficinas como atividade educativa sustentável}

Os usuários percebem que as oficinas representam uma atividade educativa sustentável, uma vez que contribuem para a importância de separar o lixo adequadamente com vistas à sustentabilidade ambiental.

Acho que é importante pra limpeza da cidade, importante também para as pessoas verem que é importante a gente separar o lixo e mostrar que dá pra fazer várias coisas com os recicláveis. (U3)

Eu acho legal aproveitar o lixo produzido aqui no hospital, também ajuda no meio ambiente. (U5)

Eles consideram que por meio dessas atividades educativas, torna-se possível disseminar o conhecimento acerca da importância em separar e reaproveitar adequadamente os resíduos recicláveis provenientes de uma instituição hospitalar. Referem que as oficinas representam uma atitude importante para a preservação do meio ambiente, que, por sua vez, favorece a manutenção das condições de limpeza da cidade.

\section{Influência das mídias sociais}

Os usuários percebem a contribuição das mídias sociais na educação dos indivíduos em relação à cultura de separar os resíduos adequadamente.

Esses dias eu estava vendo na TV e estavam vendo quem colocaria no lixo certo que tinha um que dizia lixo reciclável e ninguém colocou, e isso aí vai mostrar para as pessoas, que é importante a gente separar o lixo, eu acho que o importante é mostrar que dá pra fazer várias coisas com os recicláveis. (U9)

Na TV a gente vê as reportagens que mostram como as pessoas inventam coisas com os lixos. Tampinha de garrafa fazem bonecos e levam para as crianças dos lar brincarem. (U14)

Percebe-se no relato acima que o usuário apresenta conhecimento acerca da separação dos resíduos, adquirido através de mídias sociais como a televisão. Menciona que, embora, tendo o local adequado para o descarte correto dos resíduos, alguns sujeitos descartam de forma errada, evidenciando-se, assim, que a questão dos resíduos ainda precisa ser trabalhada com mais precisão para que a população adquira o habito da separação adequada. Com isso, é possível afirmar que a televisão, neste caso, configurou-se em uma atividade educativa para os usuários, atentando para a ausência cultural de separar, reaproveitar e destinar adequadamente tais resíduos. 


\section{DISCUSSÃO}

O uso de substâncias psicoativas provoca algumas limitações em relação à liberdade dos usuários, pois ficam limitados em suas rotinas e, na maioria das vezes, a substância passa a ser o principal foco e interesse, repercutindo no dia-a-dia das suas relações sociais. ${ }^{7}$ Ao apreciar as limitações dos usuários, percebeu-se que as oficinas propiciaram a eles uma oportunidade para expressarem seus sentimentos, tornando-se possível resgatar um pouco da liberdade perdida durante o uso das substâncias, bem como a sua ressocialização.

Os usuários de substâncias psicoativas possuem diversas perdas provenientes de seus delitos e infrações cometidas enquanto buscam alimentar o vício. ${ }^{7}$ Esses usuários não sofrem apenas perdas físicas, mas sim, de valores, como perda da confiança, dignidade e respeito da família, amigos e sociedade. Os sentimentos de perda retratam frustração, depressão e falta de vontade de viver. ${ }^{2}$

É fundamental a efetividade de políticas públicas que visem capacitar, educar e ocupar os jovens, no propósito de minimizar as repercussões associadas ao uso de substâncias psicoativas entre adolescentes. ${ }^{7}$ Nessa direção, pressupõe-se que as oficinas desenvolvidas com os usuários, podem contribuir para aquisição de responsabilidades, para atuar e tomar decisões, favorecendo a eficácia durante e após o tratamento. Durante o tratamento de cada usuário, além de cuidados essenciais por parte dos profissionais, requer uma reabilitação bio-psico-socio-espiritual, com o propósito de auxiliar não somente o tratamento medicamentoso, mas também cuidados que vão muito além, no sentido de permitir com que os usuários se sintam seguros e confiantes quanto seu tratamento e reabilitação. ${ }^{8}$

Por meios das oficinas foi possível atribuir responsabilidades aos usuários, uma vez que se sentiram livres para transformar os resíduos recicláveis em novos produtos/artesanatos, constituindose em uma oportunidade de construção e aprendizado. Essas construções representam subsídios de ocupação e recursos financeiros, tanto para o momento que se encontram internados na unidade, quanto para o período após alta hospitalar. ${ }^{7}$

Essas ações educativas auxiliam na formação de indivíduos pensantes e éticos, visando à transformação social em prol de 
um mundo mais justo, solidário e humano. ${ }^{9}$ Ainda, contemplam os aspectos para uma aprendizagem efetiva, no sentido de que chama a atenção para um assunto emergente. Os significados dessas ações promovem a discussão entre os participantes e o conhecimento gerado, onde a partir da atividade pode ser transportado para a dimensão da realidade, denotando-se a transcendência. ${ }^{10}$

Os usuários percebem as oficinas como atividade educativa sustentável, tendo em vista que por meio dessas, é possível disseminar o conhecimento acerca da importância em separar e reaproveitar adequadamente os resíduos recicláveis provenientes de uma instituição hospitalar. Enfatizam o favorecimento dessas atividades para a preservação do meio ambiente, bem como para a manutenção das condições de limpeza da cidade. Convém lembrar, que uma cidade limpa, nesse caso, com ausência de resíduos descartados nas ruas, minimiza a proliferação de microrganismos oriundos desses resíduos, e, assim, contribui favoravelmente para diminuir 0 aparecimento de algumas doenças. ${ }^{8}$ Tal atitude colabora para o impacto visual positivo deste meio, favorecendo a saúde socioambiental desses indivíduos. ${ }^{7}$

Ao atentar para o meio em que o indivíduo usuário encontra-se inserido, é relevante que os profissionais de saúde incorporem as questões ambientais nas discussões que envolvem o processo saúde/doença. ${ }^{9}$ É preciso considerar o campo acerca do meio ambiente perante as atividades desenvolvidas no âmbito do serviço de saúde, além de promover ações estratégicas voltadas para o (re)pensar das práticas em saúde e suas consequentes implicações para a sustentabilidade ambiental. $^{11}$

Corroborando com as falas dos usuários, destaca-se que o processo de reciclagem contribui significativamente para a preservação do planeta, pois permite diminuir a poluição do solo, da água e do ar. ${ }^{7}$ Por isso, cada vez mais a sociedade percebe a importância da questão ecológica, reciclando materiais como uma forma de minimizar o descarte e reduzir os custos de produção, colaborando com um ambiente saudável. ${ }^{9}$

Os produtos descartados podem ir para um local de descarte seguro, como aterros sanitários e depósitos específicos, caso contrário, irão para um destino não 
seguro, sendo lançado na natureza, onde irá poluir o ambiente e voltar a uma cadeia de distribuição reversa. ${ }^{7} \mathrm{O}$ ideal é que se tenha a reciclagem como destino do produto, $\mathrm{o}$ seu reprocessamento $\mathrm{e}$ devolução ao mercado. Se não tiver mais nenhuma alternativa de ser reaproveitado, o descarte será na forma de lixo em algum depósito específico. ${ }^{12}$

Com base na percepção dos usuários, foi possível observar que na sociedade contemporânea prevalece à ausência da cultura da separação adequada dos resíduos. Tal fato faz-se repensar sobre o conceito que a maioria dos indivíduos possui acerca dos resíduos como algo sujo e inútil em sua totalidade, considerando que grande parte dos materiais que vão para o lixo, podem/devem ser reaproveitados ou reciclados. Para tanto, percebe-se a contribuição das mídias sociais na educação dos indivíduos em relação à cultura de separar os resíduos adequadamente. $^{9}$

Ao adentrar na importância atribuída às mídias sociais no contexto dos resíduos, acredita-se que seja necessário aumentar a disseminação desse conhecimento através dos meios de comunicação mais acessados pelos atores sociais contemporâneos. ${ }^{8}$
Entre esses recursos, merece destaque a internet, a televisão, os jornais, os rádios e as revistas, os quais, em conjunto com as demais mídias sociais, são responsáveis em transmitir informações pertinentes aos seus telespectadores. $^{7}$

A propagação do recurso da televisão foi um dos fenômenos mais importantes da história recente. Este pode exercer uma ampla influência no homem moderno, principalmente no âmbito de suas atitudes, valores e comportamento. ${ }^{10}$ No contexto atual, a televisão faz parte da vida do ser humano, acompanhando o percurso existencial, servindo, muitas vezes, como mecanismo de socialização para orientar ações e padrões de consumo. ${ }^{13}$ Os meios de comunicação possuem o papel social de informar, entreter e difundir cultura ao público acerca de temas de seu interesse. Dentre essas funções, está o papel de educar, que pode ser executado através de programas educativos. ${ }^{14}$

No contexto dos usuários de substâncias psicoativas a educação socioambiental representa uma importante ferramenta, sobretudo, quando essa estiver voltada para um agir ecológico. Uma atitude ecológica é mais do que a soma de bons comportamentos, é necessário saber 
por que agir ou não agir, em outras palavras, as motivações para determinada atitude. ${ }^{7}$ É importante ponderar que o agir envolve a tomada de decisões e que não é algo que está apenas no âmbito da racionalidade, porém envolve igualmente sentimentos. $^{4}$

$\mathrm{O}$ aprofundamento de conhecimentos sobre a problemática ecológica, tanto no âmbito da formação profissional como por meio da educação permanente, é fundamental para promover uma reavaliação de visões, posições e ações, de forma a conduzir o trabalhador ao desenvolvimento de ações mais responsáveis com o meio ambiente. ${ }^{15}$

Com isso, cabe aos profissionais da saúde considerar a importância do cuidado ecológico em sua amplitude e complexidade, e, constantemente, buscar maiores subsídios para agir consciente e responsavelmente com vistas à preservação ambiental e a valorização dos determinantes ambientais no processo de assistência à saúde das populações. ${ }^{4}$

Salienta-se a necessidade de travessia do antropocentrismo ao ecologicentrismo, por meio de percepção sistêmica de que somos seres de interações e associações e que mantemos uma relação de dependência e influência com todos os demais seres e o meio ambiente. $\mathrm{O}$ homem precisar transcender o mundo singular e promover ações que ultrapassam a singularidade, resgatando o sentimento que pertença à natureza. ${ }^{16}$

É necessário considerar que o cuidado do ecossistema também é um cuidado inerente aos profissionais de saúde, que se preocupa e preserva a vida do homem e da natureza, tendo em vista que adversidades ambientais também podem ser percebidas como possíveis problemas de saúde. Para tanto, somente com base numa percepção integradora entre homem-natureza, saúde-ambiente é que se pode estabelecer uma relação complexa de cuidados. ${ }^{17}$

\section{CONCLUSÕES}

Ao conhecer o significado das oficinas de artesanatos com materiais recicláveis para usuários em tratamento de desintoxicação de substâncias psicoativas foi possível conhecer os sentimentos do vivido dos usuários, a importância das oficinas de materiais recicláveis como atividade educativa sustentável e ainda compreender a contribuição das mídias 
sociais na cultura da separação dos resíduos.

Acredita-se na importância da inserção dos profissionais de saúde nesse processo, ou seja, do comprometimento desses profissionais no que diz respeito às estratégias de educação continuada em saúde que vise o sujeito como um todo, integrando prevenção, promoção, proteção e recuperação da saúde. Salienta-se, a importância em promover continuamente atividades voltadas para as preocupações emergentes que dizem respeito à saúde socioambiental.

No contexto hospitalar, mediante o aumento de usuários de substâncias psicoativas em tratamento para desintoxicação, cabe aos profissionais de saúde ponderar que estratégias preventivas são menos onerosas e que minimizam os danos á saúde socioambiental. Ainda, é fundamental adotar atitudes educativas e empreendedoras com vistas a reduzir as manifestações diretas do uso de substâncias psicoativas e despertar uma consciência socioambiental, na busca do viver saudável dos indivíduos em sua singularidade.

Para tanto, o profissional de saúde como interlocutor do cuidado humano e ecológico, precisa estar sempre promovendo a educação nos diferentes cenários de atuação com vistas à promoção de saúde pública e da sustentabilidade de nosso planeta. Este estudo limita-se ao compartilhar uma experiência realizada em uma instituição hospitalar, por este motivo não retrata uma realidade generalizada. Para tanto, novos estudos devem ser realizados com a finalidade de propor o desenvolvimento de oficinas com este grupo em específico.

Salienta-se que a realização deste estudo apresenta algumas limitações, como ser delimitada em um único cenário, bem como no tempo em que foi desenvolvida. Assim, não se pretende generalizar os resultados, no entanto, sua contribuição está no aprofundamento da temática estudada, o que revela a importância desta pesquisa.

\section{REFERÊNCIAS}

1. Carlini EA, coordenador. Levantamento domiciliar sobre o uso de drogas psicotrópicas no Brasil: estudo envolvendo as 108 maiores cidades do Brasil, 2005 [internet]. São Paulo: CEBRID, UNIFESP; 2006 [citado em 10 jan 2017]. Disponível em: http://www.cebrid.com.br/wpcontent/uploads/2014/10/II-Levantamento- 
Domiciliar-sobre-o-Uso-de-DrogasPsicotr\%C3\%B3picas-no-Brasil.pdf 2. Siqueira DF, Moreschi C, Backes DS. Vivendo em função da droga/crack: vivências de usuários. Nursing (São Paulo) [Internet]. 2012 [citado em 10 jan 2017]; 14(166):136-40. Disponível em: http://bases.bireme.br/cgibin/wxislind.exe/iah/online/?IsisScript=iah /iah.xis\&src=google\&base=LILACS\&lang $=$ p\&nextAction $=$ lnk\&exprSearch $=620783$ \&indexSearch=ID

3. Backes MTS, Erdmann AL, Backes DS. Cuidado ecológico: o significado para profissionais de um hospital geral. Acta Paul Enferm. [Internet]. 2009 [citado em 10 jan 2017]; 22(2):183-91. Disponível em:

http://www.scielo.br/pdf/ape/v22n2/a11v2 2n2.pdf

4. Camponogara S. Saúde e meio ambiente na contemporaneidade: o necessário resgate do legado de Florence Nightingale. Esc Anna Nery Rev Enferm. [Internet]. 2012 [citado em 10 jan 2017]; 16(1):17884. Disponível em: http://www.scielo.br/pdf/ean/v16n1/v16n1 a24.pdf

5. Bardin, L. Análise de conteúdo. 70ed. Lisboa, Portugal: LDA; 2011.

6. Conselho Nacional de Saúde (Brasil). Resolução ${ }^{\circ} 466$, de 22 de dezembro de 2012. Aprova as diretrizes e normas regulamentadoras de pesquisas envolvendo seres humanos [Internet]. Brasília, DF: CNS; 2012 [citado em 10 jan 2017]. Disponível em: http://conselho.saude.gov.br/resolucoes/20 12/Reso466.pdf

7. Costa AG, Camurça VV, Braga JM, Tatmatsu DIB. Drogas em áreas de risco: o que dizem os jovens. Physis [Internet]. 2012 [citado em 10 jan 2017]; 22(2):80319. Disponível em: http://www.scielo.br/pdf/physis/v22n2/21. pdf

8. Siqueira DF, Moreschi C, Pozzobon L, Vedoin PC. Adolescente usuário de crack: relato de experiência. Rev Enferm UFSM. [Internet]. 2012 [citado em 10 jan 2017]; 2(2):456-63. Disponível em:

https://periodicos.ufsm.br/reufsm/article/vi ew/3045/3774

9. Costa SP, Chavaglia SRR, Amaral SEM, Silveira RE. Internações e gastos relacionados ao suicídio em um hospital público de ensino. Rev Enferm Atenção Saúde [Internet]. 2016 [citado em 10 jan 2017]; 4(2):20-32. Disponível em: http://seer.uftm.edu.br/revistaeletronica/ind ex.php/enfer/article/view/1104 10. Coscrato G, Pina JC, Mello DF. Utilização de atividades lúdicas na educação em saúde: uma revisão integrativa da literatura. Acta Paul Enferm. [Internet]. 2010 [citado em 10 jan 2017]; 23(2):257-63. Disponível em: http://www.producao.usp.br/bitstream/han dle/BDPI/2945/art_COSCRATO_Utilizaca o_de_atividades_ludicas_na_educacao_em 2010.pdf? sequence $=1$

11. Moreschi C, Siqueira DF, Dalcin CB, Grasel JT, Backes DS. Homenagem a Florence Nightingale e compromisso com a sustentabilidade ambiental. Rev Baiana Enferm. [Internet]. 2011 [citado em 10 jan 2017]; 25(2):203-8. Disponível em: https://portalseer.ufba.br/index.php/enferm agem/article/view/5260

12. Almeida AS, Furegato ARF. Papéis e perfil dos profissionais que atuam nos serviços de saúde mental. Rev Enferm Atenção Saúde [Internet]. 2015 [citado em 10 jan 2017]; 4(1):79-88. Disponível em: http://seer.uftm.edu.br/revistaeletronica/ind ex.php/enfer/article/view/1265

13. Vidigueira VCR. A influencia da televisão no desenvolvimento sócioemocional dos adolescentes [Internet]. 
[Trabalho de Conclusão de Curso].

Faculdade de Ciências Humanas e Sociais

da Universidade do Algarve: Algarve,

Portugal; 2006 [citado em 10 jan 2017].

Disponível em:

http://www.psicologia.pt/artigos/textos/TL

0061.pdf

14. Junqueira MAB, Santos MA, Pillon

SC. Competências atitudinais de estudantes

de enfermagem na assistência a usuários de

álcool. Rev Enferm Atenção Saúde

[Internet]; 2014 [citado em 10 jan 2017];

3(2):76-85. Disponível em:

http://seer.uftm.edu.br/revistaeletronica/ind

ex.php/enfer/article/view/1022

15. Camponogara S, Ramos FRS, Kirchhof

ALC. A problemática ecológica na visão

de trabalhadores hospitalares. Ciênc Saúde

Colet. [Internet]. 2011 [citado em 10 jan

2017]; 16(8):3561-70. Disponível em:

http://www.scielo.br/pdf/csc/v16n8/a24v16

n8.pdf

16. Backes MTS, Backes DS, Drago LC,

Koerich MS, Erdmann AL. Do

antropocentrismo ao ecologicentrismo:

formação para o cuidado ecológico na

saúde. Rev Gaúcha Enferm. [Internet].

2011 [citado em 10 jan 2017]; 32(2):263-9.

Disponível em:

http://www.scielo.br/pdf/rgenf/v32n2/a08v

32n2.pdf

17. Baggio MA, Callegaro GD, Erdmann

AL. Significando o cuidado

ecológico/planetário/coletivo/do ambiente

à luz do pensamento complexo. REME

Rev Min Enferm. [Internet]. 2011 [citado

em 10 jan 2017]; 15(1):11-8. Disponível

em:

http://www.reme.org.br/artigo/detalhes/2

RECEBIDO: 06/02/2017

APROVADO: 19/06/2018

PUBLICADO: 07/2018 